\title{
Uma análise da escolha do curso superior no Brasil
}

\author{
Felipe dos Santos Martins* \\ Danielle Carusi Machado ${ }^{* \star}$
}

O objetivo do artigo é avaliar os fatores que influenciam a escolha do tipo de curso superior no Brasil. A partir dos dados dos Censos Demográficos de 2000 e 2010 e da Sinopse de Educação Superior de 2000, modelamos a escolha do curso por parte do indivíduo usando o modelo logit condicional. As variáveis que condicionam esta escolha são: características individuais e familiares; relação candidato-vaga; tempo de duração do curso; e incentivos econômicos das carreiras (média e variabilidade do rendimento e desemprego). Esta análise é feita para o total de indivíduos que estavam em idade de prestar vestibular no ano de 2000 . Os resultados indicam que os rendimentos e a taxa de desemprego influenciam apenas os indivíduos do quartil mais elevado, enquanto a concorrência possui maior impacto sobre a escolha dos indivíduos do quartil inferior de distribuição.

Palavras-chave: Ensino superior. Capital humano heterogêneo. Acesso ao ensino superior.

\footnotetext{
*Instituto de Pesquisa Econômica Aplicada (Ipea), Rio de Janeiro-RJ, Brasil (felipe.martins@ipea.gov.br; https://orcid. org/0000-0001-7146-8047).

** Universidade Federal Fluminense (UFF), Niterói-RJ, Brasil (dani_carusi@hotmail.com; https://orcid.org/0000-00022556-0886).
} 


\section{Introdução}

Existe uma forte influência da educação no nível de rendimentos no Brasil, sendo que, entre os motivos mais apontados pela literatura brasileira, estão a grande sensibilidade dos salários em relação à escolaridade do trabalhador e a elevada desigualdade educacional da mão de obra brasileira. A partir de dados do Censo Demográfico 2010, verifica-se que os indivíduos ocupados com o ensino superior completo recebiam, em média, 2,5 vezes ${ }^{1}$ o rendimento médio dos trabalhadores com escolaridade de nível médio completo. Além disso, trabalhadores com o ensino superior completo registram menores taxas de desemprego, dentre outras vantagens psicológicas e sociais. Todavia, em 2010, no Brasil, apenas $12,1 \%$ da população ocupada entre 25 e 65 anos de idade possuía tal nível de formação. De acordo com os dados da Pesquisa Nacional por Amostra de Domicílios (PNAD), este percentual passou para $16,6 \%$ em 2015 . Houve também uma expansão significativa do número de matrículas e vagas no ensino superior.

Este movimento é explicado, em grande medida, por uma série de políticas que incentivaram as transições para a educação superior, seja no sistema público, seja no privado.

Merecem destaque os programas criados para financiar os estudos de pessoas de classes de renda mais baixa em universidades particulares. Em 2005, foi criado o Programa Universidade para Todos (Prouni), que fornecia bolsas parciais e integrais para estudantes custearem seus estudos em instituições de ensino superior (IES) particulares. Ampliaram-se, igualmente, os empréstimos pelo Fundo de Financiamento Estudantil (Fies), também, direcionados ao custeio do ensino superior para alunos de baixa renda.

Em outra vertente, na linha de tornar a universidade pública mais democrática e inclusiva, surgiram as políticas de cotas - raciais ou que priorizavam a renda ou a educação em escola média pública - para minimizar o problema de acesso limitado de determinado grupo de pessoas ao ensino superior. As ações afirmativas eram entendidas como compensatórias, no intuito de minimizar as desigualdades históricas no acesso à educação superior de indivíduos com base na sua cor/raça/etnia ou classe. Inicialmente, a adoção de cotas para o ingresso na educação superior foi aplicada de forma descentralizada em algumas universidades, surgindo primeiramente a Universidade Estadual do Estado do Rio de Janeiro (UERJ), em 2003. ${ }^{2}$ A partir desta data, tal ação afirmativa culminou com a Lei de Cotas que foi sancionada em $2012 .^{3}$

Outro conjunto de ações direcionadas às universidades públicas compunha o Programa de Apoio aos Planos de Reestruturação e Expansão das Universidades Federais (Reuni) de

\footnotetext{
${ }^{1}$ Vale ressaltar também que as habilidades desenvolvidas durante cada curso superior são específicas, gerando acúmulo de capitais humanos distintos e, consequentemente, diferenças nos retornos do mercado de trabalho das pessoas com o ensino superior completo.

${ }^{2}$ Mendes Junior (2014) descreve o programa implementado na UERJ e mostra que os alunos cotistas dão um alto valor ao curso, evadindo menos e tendo uma maior taxa de conclusão.

${ }^{3}$ A Lei de Cotas determinou que as universidades, os institutos e centros federais devem reservar $50 \%$ das suas vagas para estudantes oriundos de escola pública e, dentre estas, haverá reserva de um percentual a estudantes negros (autoidentificados como de cor "parda" ou "preta") e indígenas.
} 
2007. Este programa tinha como objetivo principal a criação de condições para a ampliação do acesso e permanência do estudante na educação superior, no nível de graduação, bem como o melhor aproveitamento da estrutura física e dos recursos humanos existentes nas universidades federais. Em resumo, o Reuni ampliou o número de vagas nas universidades públicas e expandiu a rede de universidades. A forma como foi conduzida esta expansão foi bastante questionada, não tendo sido realizados um planejamento prévio e nem uma avaliação criteriosa de necessidades, segundo Schwartzman (2010). Contudo, claramente, o impacto desta política foi uma maior ampliação da rede pública, sobretudo em áreas mais afastadas dos grandes centros urbanos.

No caso específico do processo de seleção para as vagas das universidades públicas, além das políticas de ações afirmativas, houve uma mudança logística importante que foi a implementação do Sistema de Seleção Unificada (Sisu), ${ }^{4}$ em 2010, e o uso do Exame Nacional do Nível Médio (Enem), criado em 1998, para determinar a entrada na universidade, sobretudo após 2010. 0 processo de seleção para maior parte das vagas nas universidades públicas foi centralizado com o funcionamento do Sisu. Esse, apesar do seu caráter seletivo, permitiu que o processo de escolha por parte dos estudantes fosse mais democratizado. ${ }^{5}$ Estudantes de diferentes localidades poderiam fazer escolhas universitárias em todo território, amplificando o leque de oportunidades.

Nesse contexto de mudanças institucionais ao longo dos anos 2000 no Brasil, sabemos que os jovens que finalizam o ensino médio, usualmente com duração de três anos, precisam decidir se ingressam diretamente na atividade econômica ou se seguem estudando. Os cursos técnicos/profissionalizantes não são tão comuns, ${ }^{6}$ logo, a continuidade dos estudos dependeria da entrada numa instituição de ensino superior. 0 acesso ao ensino superior no Brasil, entretanto, como dito anteriormente, não é livre. Seguir a carreira universitária, portanto, envolve uma decisão relativa ao estudo para o exame de acesso, seja nos moldes atuais (Enem), seja no modelo tradicional anterior. Como as qualidades dos ensinos médio e fundamental diferem de forma significativa pelas classes de renda no Brasil, as aspirações com relação ao ingresso no ensino superior acabam sendo influenciadas pelas condições socioeconômicas.

A transição do ensino médio para o superior é marcada por um alto grau de seletividade. Conforme Mont’Alvão (2011, p. 3), há “um alto grau de desigualdade nas chances de se completar as transições educacionais, tanto na rede pública quanto na rede privada". O fenômeno de estratificação educacional, ou seja, a importância da origem social para

\footnotetext{
${ }^{4}$ O Sisu consiste numa plataforma online em que as instituições públicas de ensino superior ofertam suas vagas aos estudantes selecionados apenas com base na nota obtida no Enem. A adesão de cursos e IES ao sistema de seleção foi feita gradualmente, contudo, em 2015, grande parte das instituições já estava operando a seleção de forma centralizada, conforme Machado e Szerman (2016).

${ }^{5}$ Para analisar os efeitos do Sisu sobre a inserção dos estudantes no ensino superior, ver Li e Chagas (2017) e Machado e Szerman (2016). Os autores mostram que a migração dos estudantes foi intensificada.

${ }^{6}$ De acordo com Aguas e Machado (2016, p.4), “apenas 14\% das pessoas entre 25 a 55 anos no Brasil e com exatamente o ensino médio completo já frequentaram algum curso de nível técnico”.
} 
determinar o alcance educacional dos indivíduos se configura ainda na sociedade brasileira, apesar de avanços em termos de políticas públicas para a promoção do ingresso de pessoas de classe mais baixa na universidade. A maior parte dos alunos que ingressam no ensino superior vem das camadas mais ricas da população. Ou seja, a escolha do curso universitário ocorre muitas vezes a partir de um processo de autosseleção do candidato, que segue uma determinada hierarquização de cursos. Segundo Nogueira (2012, p. 7), "os indivíduos não se distribuem aleatoriamente entre os diversos cursos em função de supostas preferências ou interesses de natureza idiossincrática. Ao contrário, essa distribuição está estatisticamente relacionada às características sociais, ao perfil acadêmico, à etnia, gênero e idade do estudante".

Portanto, ao término do ensino médio, os indivíduos escolhem entre demandar ou não escolaridade de nível superior, considerando a possibilidade de sucesso ou não no exame de ingresso. Nesse sentido, a carreira a ser seguida pode ser influenciada por tal probabilidade de sucesso no ingresso e na continuidade do curso, bem como por outros aspectos relativos às preferências individuais ou perspectivas profissionais futuras.

Internacionalmente, muitos estudos exploram o impacto da origem social e das características intrínsecas do indivíduo, aptidões e remuneração esperada no mercado de trabalho na escolha por carreira e demanda por escolaridade. Dentre muitos, destacam-se os trabalhos de Freeman (1976), Berger (1988), Paglin e Rufolo (1990), Altonji (1993) e Altonji, Blom e Maghir (2012), os quais apontaram que o rendimento esperado, do período inicial da carreira ou ao longo da ocupação no mercado de trabalho, dos cursos superiores impacta positivamente a tomada de decisão dos indivíduos por qual curso superior ingressar.

Outra questão ligada à temática, porém menos abordada, é a probabilidade de sucesso no curso superior escolhido. Duru e Mingat (1979) partiram do pressuposto de que a escolha pela carreira é significativamente afetada pelo rendimento no mercado de trabalho, conforme apontado pelos trabalhos anteriormente destacados, e incorporaram no modelo a probabilidade de sucesso no curso escolhido. 0 trabalho mostrou que os alunos de classes mais elevadas da sociedade francesa possuíam maior propensão a disputarem as vagas nas escolas de ensino superior mais prestigiadas do que os alunos de classes mais humildes, que obtiveram as mesmas notas nos processos seletivos. Este resultado está em conformidade com a ideia de existência de estratificação educacional na escolha dos cursos superiores. Fenômeno que também ocorre para o caso do Brasil.

Seguindo na mesma linha, Montmarquette, Cannings e Mahseredjian (2002) analisaram o processo de tomada de decisão do indivíduo em duas etapas: a importância da probabilidade de sucesso no curso escolhido; e o rendimento esperado pela formação recebida. Dessa forma, para embasar a escolha a ser realizada, os indivíduos estimariam o retorno futuro de cada carreira, assim como a probabilidade de sucesso em cada uma delas, baseados nas suas preferências e aptidões. Em seguida escolheriam o curso que possuísse a maior utilidade esperada. 0 resultado do estudo apontou que as mulheres são 
menos influenciadas pela renda esperada do que os homens e que há uma significativa diferença no impacto da renda esperada por cor e sexo.

No Brasil, este tema é usualmente estudado considerando o ensino superior como um todo, ou seja, sem discriminar o tipo de curso superior escolhido pelo indivíduo, como o trabalho de Carvalho (2011), ou por meio de estudos de casos em universidades específicas, como, por exemplo, os trabalhos de Emílio, Belluzzo Junior e Alves (2004), Casari (2006), Bartalotti e Menezes-Filho (2007), Soares (2007) e Silva e Neto (2015). Na tentativa de identificar os determinantes ao ingresso no ensino superior, Carvalho (2011) e Emílio, Belluzzo Junior e Alves (2004) apontaram os fatores socioeconômicos como principais motivadores no processo seletivo. Por outro lado, os demais estudos indicaram que fatores referentes à remuneração futura são determinantes no processo decisório. Silva e Neto (2015) mostram que a escolha das carreiras é influenciada positivamente também pela participação no emprego total e negativamente pela variabilidade salarial.

Neste artigo analisam-se as escolhas do tipo de curso superior realizadas pela pequena parcela da população brasileira que decide seguir estudando e que passa no exame de acesso às instituições de ensino superior. Dadas as limitações da base de dados, que serão discutidas na seção metodológica, não são traçados os determinantes da escolha de ingressar ou não no ensino superior. 0 objeto de análise é lançar luz sobre as motivações pessoais e econômicas que movem um indivíduo a ir para uma ou outra carreira universitária e concluí-la.

A partir do modelo econométrico logit condicional, será estimada a probabilidade de os indivíduos seguirem determinadas carreiras de ensino superior, considerando o efeito de: características individuais e familiares que procuram traçar alguns aspectos relativos às preferências individuais e ao contexto familiar; características relativas à institucionalidade dos diferentes cursos - relação candidato/vaga (concorrência) e tempo de duração do curso -; e incentivos econômicos das carreiras, delineados a partir das variáveis de rendimento (média e variabilidade) e de inserção no mercado de trabalho (desemprego). Esta análise é feita para o total de indivíduos que estavam em idade de prestar vestibular em 2000, sendo segmentada por quartil de renda domiciliar per capita $(r d p c)$. São explorados alguns aspectos da escolha e da permanência/conclusão do curso de ensino superior por parte dos indivíduos e se este processo difere conforme as suas condições socioeconômicas.

São usadas as informações dos Censos Demográficos 2000 e 2010 (IBGE), pois constituem as únicas bases de dados com informação detalhada sobre a formação superior do indivíduo para todo o país. Para complementar a análise, utilizam-se as informações obtidas nas Sinopses do Ensino Superior (INEP, 2012), construindo um panorama da oferta e demanda de vagas no ensino superior, assim como uma análise da relação candidato/vaga.

Após esta introdução, o trabalho apresenta a base de dados que será utilizada, bem como uma breve análise descritiva do ensino superior brasileiro em 2000 e 2010 e do perfil dos concluintes do ensino superior. Posteriormente são analisados os resultados e, por fim, registradas as principais conclusões. Uma ressalva à nossa análise é que sabemos, de 
antemão, conforme já descrito anteriormente, que o cenário institucional foi modificado ao longo deste período recente, contudo, acreditamos na relevância de descrever este comportamento mesmo diante destas mudanças. Nas considerações finais, portanto, traçamos alguns comentários sobre isso e algumas implicações que teriam nos nossos resultados.

\section{Bases de dados}

Em função do objetivo do presente trabalho, são utilizados os dados dos Censos Demográficos de 2000 e 2010, elaborados pelo Instituto Brasileiro de Geografia e Estatística (IBGE), e as Sinopses do Ensino Superior de 2000 a 2010, fornecidas pelo Instituto Nacional de Estudos e Pesquisas Educacionais Anísio Teixeira (Inep).

A Sinopse é elaborada com base no Censo do Ensino Superior, realizado anualmente, e apresenta um conjunto de tabelas contendo informações sobre os cursos superiores nacionais. 0 trabalho utiliza dados sobre número de cursos, de matrículas, de vagas oferecidas, de candidatos inscritos e de ingressantes, segmentados por unidades da federação, categorias administrativas e áreas dos cursos presenciais. Estas variáveis são importantes para delimitar um cenário sobre o ensino superior no Brasil no período considerado e para a construção das variáveis de concorrência por tipo de curso superior.

A utilização do Censo Demográfico se justifica por ser a única pesquisa domiciliar que possui, no questionário amostral, um levantamento sobre o curso superior do indivíduo, caso o mesmo tenha completado esse nível de ensino. Apesar de a pergunta ser feita apenas para os que concluíram seus estudos no nível superior, admite-se que a sua análise pode lançar luz sobre alguns aspectos do processo de escolha dos indivíduos com relação aos cursos superiores.

A base do Censo Demográfico de 2000 é utilizada para o cálculo das variáveis relativas às perspectivas futuras da carreira profissional escolhida, ou seja, o rendimento esperado e a trajetória de inserção no mercado de trabalho. No momento que o jovem, em 2000, decide ingressar no ensino superior, ele avalia as condições relativas ao mercado de trabalho da carreira que seguirá olhando a situação daqueles jovens que acabaram de se formar e entraram no mercado de trabalho.

Logo, a partir desta base, são calculadas as seguintes variáveis para cada curso superior:

- rendimento inicial esperado - calculado com base no rendimento-hora do trabalho principal das pessoas ocupadas com 25 a 30 anos de idade;

- taxa de desemprego - construída a partir do desemprego observado para as pessoas com o ensino superior completo no Censo Demográfico 2000;

- variabilidade salarial - calculada a partir do desvio padrão do rendimento por hora do trabalho principal de pessoas ocupadas com o ensino superior completo no Censo Demográfico de 2000. 
É importante destacar que os Censos Demográficos disponibilizam três níveis de detalhamento para o curso superior: um nível mais minucioso, com 100 áreas de formação; um nível intermediário, com 23 áreas específicas; e outro nível mais agregado, com oito áreas gerais. Para uma análise mais rica e estatisticamente representativa, criou-se uma nova tipologia de formação com 17 grupos, compatibilizando as informações do Censo Demográfico de 2000 e $2010 .^{7}$

Assim, as variáveis de incentivos econômicos sobre os cursos superiores foram calculadas com base no Censo Demográfico de 2000. Tendo em vista que a partir dos Censos Demográficos não é possível precisar o ano de ingresso do indivíduo no ensino superior, para estimar as probabilidades de escolha dos cursos optamos por restringir a amostra para os indivíduos que estavam em idade de prestar vestibular em 2000 (entre 26 e 28 anos, em 2010) e que já tinham alcançado o nível superior em 2010. Estes jovens seriam os que estavam no processo decisório de qual curso ingressar, observando a realidade reportada nos dados do Censo Demográfico de 2000. Ou seja, construímos uma coorte hipotética tendo em vista que a base de dados utilizada não permite acompanhar os indivíduos ao longo do tempo. Nesse sentido, são necessárias algumas considerações sobre a amostra escolhida. Primeiro, pode haver indivíduos que passaram por diferentes graduações e não somente o último curso declarado no Censo Demográfico. A decisão deste indivíduo, portanto, não foi tomada olhando exclusivamente o cenário delineado pelas variáveis do Censo Demográfico. Segundo, a escolha universitária feita em 2000 pode ser diferente da que se encontra reportada em 2010. Isso pode ser ainda mais grave se ampliamos muito a faixa etária analisada, o que aumenta mais as possibilidades do processo de escolha dos indivíduos. Restringindo a amostra aos indivíduos nas faixas etárias mais jovens e limitando aos que terminaram o nível superior, acreditamos que estes tipos de problemas sejam minimizados. 0 fato de aumentarmos o tamanho da amostra também fragiliza um pouco as variáveis de interesse no processo de decisão do indivíduo. Quanto maior for o leque de idade, maior será o número de casos de pessoas que tomam as decisões olhando não exclusivamente para estas variáveis, mas também para outras relativas às restrições de renda ou da família, as quais não se encontram no nosso banco de dados no momento que os indivíduos tomam esta decisão.

Existe efetivamente um trade off na escolha da amostra, pois se, por um lado, tornamos a amostra mais homogênea para entender um pouco melhor o processo decisório do curso pretendido, por outro, perdemos uma variabilidade que pode ser importante para determinar diferentes trajetórias educacionais. Se nas classes de renda mais baixa a decisão de entrar na universidade é mais tardia, devido às dificuldades na escolaridade média (maior distorção idade-série), há um viés de seleção na nossa amostra. Os mais pobres certamente estarão sub-representados. Apesar destes potenciais problemas, concentraremos a análise para a amostra de indivíduos de 26 a 28 anos em 2010, pois acreditamos

\footnotetext{
${ }^{7}$ No Anexo, apresenta-se a tabela que mostra a classificação dos cursos criada utilizando os códigos do IBGE para os dois anos disponíveis.
} 
que somente dessa forma teremos garantia da influência das variáveis construídas para o processo decisório. Ao extrapolarmos a faixa etária, as variáveis escolhidas de cenário econômico acabam perdendo força. ${ }^{8}$

Registra-se que, caso a pessoa tenha concluído o curso de mestrado ou doutorado, a informação indicada refere-se ao curso mais elevado concluído e, desse modo, para a análise econométrica, tais informações foram descartadas. Dessa maneira, para a análise econométrica, a amostra é composta apenas por indivíduos com o ensino superior completo, excluindo-se aqueles com mestrado ou doutorado completo. Assim, a amostra utilizada a partir do Censo Demográfico de 2010 contava com 76.767 indivíduos.

Ademais, retiraram-se os indivíduos cujo rendimento domiciliar per capita $(r d p c)$ foi igual a zero ou superior a cinco desvios padrão acima da média. Destaca-se que a variável de $r d p c$ foi recalculada, excluindo o rendimento do próprio indivíduo. Tal exclusão justifica-se por pretendermos utilizar esta variável apenas como uma proxy para a dotação familiar e não queremos analisar um possível trade off que possa existir entre trabalhar e estudar. Assim, ao subtrairmos a renda do próprio indivíduo, estaríamos, de certa forma, eliminando da variável renda domiciliar os incentivos econômicos associados aos ganhos no mercado de trabalho e restringido a uma descrição da situação econômica familiar, a qual pode ser um importante determinante do processo de escolha universitária, pois existe a hipótese de a escolha da carreira ser influenciada por esta situação. ${ }^{9}$ Por último, não foram consideradas as pessoas sem informações de cor, gênero e escolaridade.

A partir do Censo Demográfico de 2010, portanto, delimitamos o conjunto de informações para o qual serão estimadas as probabilidades de escolhas dos cursos superiores e as variáveis que caracterizam a família e o indivíduo:

- região de moradia - partindo da hipótese de que as escolhas ocupacionais e o tipo de curso realizado podem ser influenciados pela heterogeneidade regional, foram consideradas as cinco macrorregiões brasileiras;

- características pessoais - gênero (referência são os homens), idade, idade ao quadrado, ${ }^{10}$ cor (referência é "brancos e amarelos") e quartis da $r d p c$, deflacionada pelo Índice Nacional de Preços ao Consumidor (INPC).

Além das variáveis relativas aos chamados "incentivos econômicos”, também devemos considerar no processo de escolha do curso superior a possibilidade de sucesso no ingresso e os custos de permanência/conclusão deste curso. Dependendo da situação econômica e do histórico educacional dos indivíduos, as barreiras à entrada e permanência no curso

\footnotetext{
${ }^{8}$ Realizamos um exercício empírico para a amostra de 29 a 34 anos e as variáveis perdem significância estatística.

${ }^{9}$ Não foi adotada a informação de escolaridade dos pais para descrever a situação econômica das famílias. Apesar de a escolaridade dos pais ser considerada uma importante variável de controle nos estudos de trajetória escolar, a maioria dos indivíduos com ensino superior completo no Censo 2010 não residia nos domicílios de seus pais. Logo, não teríamos como captar estas informações.

${ }^{10} \mathrm{~A}$ inserção do termo quadrático da idade busca captar um efeito não linear da idade sobre a probabilidade de escolha dos cursos. A ideia implícita é que o efeito da idade muda conforme as faixas etárias dos indivíduos. Para os mais velhos, possivelmente um ano a mais de idade vai ter um efeito diferenciado no processo de escolha do que para aqueles mais novos.
} 
podem ser definidoras das carreiras universitárias a serem seguidas. Dessa forma, utilizando a Sinopse do Ensino Superior do ano 2000, calculamos a relação candidato/vaga para cada um dos 17 cursos selecionados, ${ }^{11}$ que serve como indicador da concorrência no processo seletivo. Cursos mais concorridos e mais custosos podem não ser cogitados como opção de carreira profissional dos indivíduos com menor poder aquisitivo e bagagem educacional.

Outra variável dos cursos superiores que usamos como proxy de custo de conclusão é a duração do curso. Seguindo o determinado pelo Conselho Nacional de Educação e pela Câmara de Educação Superior (CNE/CES) no Parecer n. 8/2007 e na Resolução n.4/2009, foi elaborada e inserida na base de dados a duração de cada um dos 17 cursos escolhidos para a análise. 0 Quadro 1 resume as variáveis utilizadas nas estimações e suas respectivas fontes de dados.

\section{QUADRO 1}

Variáveis utilizadas e fontes

\begin{tabular}{|ll|}
\hline Variáveis & Fonte \\
\hline Concorrência do curso de ensino superior & Sinopse do Ensino Superior \\
Duração do curso de ensino superior & Conselho Nacional de Educação \\
Taxa de desemprego & Censo Demográfico 2000 \\
Rendimento do início do curso & Censo Demográfico 2000 \\
Desvio padrão do rendimento/hora do início do curso & Censo Demográfico 2000 \\
Renda domiciliar per capita & Censo Demográfico 2010 \\
Curso de ensino superior & Censo Demográfico 2010 \\
Gênero & Censo Demográfico 2010 \\
Cor/raça & Censo Demográfico 2010 \\
Idade & Censo Demográfico 2010 \\
Região do Brasil & Censo Demográfico 2010 \\
\hline
\end{tabular}

Nota: No Anexo, encontra-se uma tabela com as estatísticas descritivas principais destas variáveis.

\section{Análise descritiva}

\section{Panorama do ensino superior brasileiro}

Dentre os fatores que podem influenciar o acesso ao ensino superior, destacam-se o número de vagas nas instituições de ensino superior (IES) e, particularmente, a relação candidato/vaga (concorrência no ingresso). ${ }^{12} 0$ número de vagas ofertadas no ensino superior brasileiro sofreu uma forte expansão na década de 2000, atingindo 3,1 milhões de vagas oferecidas anualmente em 2010. De acordo com os dados da Tabela 1, em dez

\footnotetext{
${ }^{11}$ A compatibilização entre os cursos da Sinopse e do Censo Demográfico é apresentada no Anexo.

${ }^{12}$ A análise descritiva da oferta e demanda de vagas no nível superior é realizada com base nas Sinopses do Ensino Superior, fornecidas pelo Inep para todo o país, entre 1991 e 2010. A Sinopse é elaborada com base no Censo do Ensino Superior, realizado anualmente, e apresenta um conjunto de tabelas contendo informações sobre os cursos superiores nacionais. 0 trabalho utiliza dados do número de cursos, de matrículas, de vagas oferecidas, de candidatos inscritos e de ingressantes, segmentados por unidades da federação, categorias administrativas e áreas dos cursos presenciais.
} 
anos, houve crescimento de $156,53 \%$ do total de vagas, graças, sobretudo, ao aumento das vagas nas IES privadas (ampliação de 176,57\% contra $81,30 \%$ das instituições públicas).

No que se refere à quantidade de alunos inscritos nos processos seletivos para as IES, em 2010 , cerca de 6,7 milhões de indivíduos concorreram para as vagas em diferentes instituições (aumento de 65,82\% no intervalo de dez anos). ${ }^{13}$

A consequência imediata disso está exposta na queda da relação candidato/vaga. De um modo geral, entre 2000 e 2010, essa relação diminuiu de 3,32 para 2,15 candidatos por vaga (Tabela 1). Tal queda foi mais acentuada nas instituições privadas e nas IES municipais, com redução de 0,67 e 0,84 candidatos/vaga, respectivamente.

TABELA 1

Vagas, inscritos, candidatos por vaga, ingressos e taxa de ocupação, segundo natureza administrativa das instituições de ensino superior

Brasil -2000-2010

\begin{tabular}{lrrrrr}
\hline \multicolumn{1}{c}{ IES } & Vagas & Inscritos & $\begin{array}{c}\text { Candidato/ } \\
\text { vaga }\end{array}$ & Ingressos & $\begin{array}{c}\text { Taxa de } \\
\text { ocupação (\%) }\end{array}$ \\
\hline $\mathbf{2 0 0 0}$ & & & & & \\
Total & 1.216 .287 & 4.039 .910 & 3,32 & 897.557 & 73,79 \\
Pública & 245.632 & 2.178 .918 & 8,87 & 233.083 & 94,89 \\
$\quad$ Federal & 120.486 & 1.156 .096 & 9,60 & 117.507 & 97,53 \\
Estadual & 96.179 & 963.113 & 10,01 & 91.727 & 95,37 \\
Municipal & 28.967 & 59.709 & 2,06 & 23.849 & 82,33 \\
Privada & 970.655 & 1.860 .992 & 1,92 & 664.474 & 68,46 \\
\hline 2010 & & & & & 50,97 \\
Total & 3.120 .192 & 6.698 .902 & 2,15 & 1.590 .212 & 91,74 \\
Pública & 445.337 & 3.364 .843 & 7,56 & 408.562 & 101,02 \\
Federal & 248.534 & 2.252 .459 & 9,06 & 251.059 & 94,01 \\
Estadual & 138.318 & 1.041 .445 & 7,53 & 130.035 & 46,97 \\
$\quad$ Municipal & 58.485 & 70.939 & 1,21 & 27.468 & 44,18 \\
Privada & 2.674 .855 & 3.334 .059 & 1,25 & 1.181 .650 & \\
\hline
\end{tabular}

Fonte: Ministério da Educação. Instituto Nacional de Estudos e Pesquisas Educacionais Anísio Teixeira; Inep (2012). Elaboração dos autores.

Já o número de ingressos no ensino superior cresceu 77,17\%, passando de 897 mil para 1,59 milhão de pessoas, entre 2000 e 2010, conforme mostra a Tabela 1 . A distribuição desses inscritos se manteve relativamente constante, sendo $25 \%$ para instituições públicas e $75 \%$ para as privadas.

Como esperado, uma vez que a taxa de crescimento da oferta de vagas foi superior ao aumento da demanda por vagas (156,53\% contra $77,17 \%$ ), a taxa de ocupação (número de ingressos dividido pelo número de vagas ofertadas) no ensino superior caiu de $73,79 \%$, em 2000, para 50,97\%, em 2010 (Tabela 1). Em outras palavras, praticamente a metade das vagas ofertadas no ensino superior no país, em 2010, não foi ocupada. Apenas as

\footnotetext{
${ }^{13}$ Nota-se que as IES federais foram as que apresentaram a maior taxa de expansão no número de inscritos, $94,83 \%$. Vale ressaltar que um único indivíduo pode estar inscrito em mais de um processo seletivo e que a taxa de crescimento das vagas foi superior à taxa de crescimento das inscrições.
} 
instituições federais apresentaram uma leve alta de 3,49 pontos percentuais no nível de ocupação, com praticamente todas as vagas ocupadas.

No tocante aos cursos específicos, a Tabela 2 apresenta a variação do número de vagas, inscrições no processo seletivo, ingressantes, relação candidato/vaga e taxa de ocupação para cada um dos cursos selecionados. Nota-se que os cursos de Línguas e de Enfermagem foram os que tiveram as maiores variações no número de vagas ofertadas, com alta de, respectivamente, $424,26 \%$ e $488,42 \%$. Já os cursos de Economia e de Matemática foram os únicos que registraram redução no número de vagas, com queda de, respectivamente, $9,63 \%$ e $51,09 \%$. Em valores absolutos, o curso de Educação possui o maior número de vagas (570 mil em 2010).

TABELA 2

Variação das vagas, dos inscritos, dos candidatos por vaga e da taxa de ocupação nas instituições de ensino superior, segundo cursos

Brasil - 2000/2010

\begin{tabular}{lrrrrr}
\multicolumn{1}{c}{ Cursos } & Vagas & Inscritos & Ingressos & $\begin{array}{c}\text { Candidato/ } \\
\text { vaga }\end{array}$ & $\begin{array}{c}\text { Taxa de } \\
\text { ocupação }\end{array}$ \\
\hline Administração & 242,29 & 127,85 & 128,57 & $-33,44$ & $-23,91$ \\
Arquitetura & 220,88 & 250,31 & 219,89 & 9,17 & $-0,21$ \\
Biologia & 197,56 & 59,16 & 74,65 & $-46,51$ & $-31,53$ \\
Computação & 161,41 & 50,54 & 67,02 & $-42,41$ & $-24,55$ \\
Contabilidade & 142,62 & 73,01 & 82,25 & $-28,69$ & $-16,69$ \\
Direito & 64,14 & 3,76 & 43,76 & $-36,79$ & $-10,33$ \\
Economia & $-9,63$ & 12,09 & $-17,19$ & 24,03 & $-4,84$ \\
Educação (1) & 104,66 & 50,35 & 25,02 & $-26,53$ & $-29,46$ \\
Enfermagem & 488,42 & 158,70 & 288,37 & $-56,03$ & $-26,75$ \\
Engenharias & 249,05 & 171,19 & 208,93 & $-22,31$ & $-8,33$ \\
Física & 72,14 & 122,98 & 92,11 & 29,53 & 8,94 \\
Fisioterapia & 177,04 & 28,76 & 50,06 & $-53,52$ & $-33,67$ \\
Jornalismo & 51,60 & $-30,68$ & $-22,66$ & $-54,28$ & $-34,41$ \\
Línguas & 424,26 & 269,34 & 411,89 & $-29,55$ & $-1,20$ \\
Matemática & $-51,09$ & $-68,61$ & $-55,02$ & $-35,82$ & $-5,86$ \\
Medicina & 66,24 & 67,60 & 78,85 & 0,82 & 7,52 \\
Publicidade & 815,32 & 281,13 & 359,48 & $-58,36$ & $-35,63$ \\
\hline
\end{tabular}

Fonte: Ministério da Educação. Instituto Nacional de Estudos e Pesquisas Educacionais Anísio Teixeira; Inep (2012).

(1) Refere-se à grande área de formação de docentes que engloba “formação de docentes para a educação básica" ou "formação de professores" (agrupando formações em licenciaturas).

Com exceção dos cursos de Matemática, Jornalismo ${ }^{14}$ e Economia, todos os demais apresentaram taxas de crescimento do número de pessoas inscritas no processo seletivo e de ingressos no curso inferiores à taxa de crescimento do número de vagas. 0 curso de Direito teve a menor taxa de crescimento no processo seletivo (3,76\%), reflexo provavelmente

\footnotetext{
${ }^{14}$ As variações no curso de Jornalismo e Publicidade podem ter sofrido impacto da padronização de nomenclatura dos cursos de Comunicação Social com a publicação das diretrizes curriculares pelo CNE em 2001, que definem habilitações específicas, tais como Jornalismo, Relações Públicas, Publicidade, etc., e também com a introdução do Sisu. Muitos cursos que anteriormente eram denominados Comunicação Social podem ter sido desmembrados ou classificados segundo outro nome.
} 
de ser um curso mais tradicional e com uma oferta de vagas já estabelecida há algum tempo. Por outro lado, o curso de Publicidade teve a maior expansão $(281,13 \%)$. Em valores absolutos, o curso de Línguas apresentou o maior aumento do número de inscritos, superando um milhão de pessoas. 0 curso de Medicina, com cerca de 550 mil inscritos, foi o segundo em quantidade absoluta. Quanto aos ingressos, os cursos de Matemática, Jornalismo e Economia registraram, entre 2000 e 2010, redução de, respectivamente, $55,02 \%, 22,66 \%$ e $17,19 \%$.

Na maioria dos cursos, a relação candidato/vaga e a taxa de ocupação das vagas tiveram retração de 2000 para 2010. As exceções foram Arquitetura, Economia, Física e Medicina, cursos com altas na relação candidato/vaga de 9,2\%, 24,0\%, 29,5\% e 0,8\%, respectivamente (Tabela 2). Vale destacar que o curso de Medicina possui a maior concorrência, com 32,91 candidatos por vaga, em 2010, enquanto o de Educação registra a menor $(1,76)$.

\section{Perfil dos indivíduos com formação superior ${ }^{15}$}

A Tabela 3 mostra algumas características dos indivíduos com formação superior, segundo o curso de graduação concluído. São várias informações a partir dos Censos Demográficos de 2000 e 2010. Um primeiro aspecto que chama a atenção é o percentual de indivíduos em cada curso. Nota-se uma grande diversidade entre os cursos, com elevada assimetria na área de formação. Cursos como Educação, Administração, Direito e Engenharias concentraram mais da metade dos indivíduos com o superior completo, enquanto Matemática, Biologia, Física e Jornalismo foram escolhidos por apenas $7 \%$ daqueles que concluíram o ensino superior.

Os dados da Tabela 3 também mostram que a maioria das pessoas com o superior completo no país $(60,79 \%)$, em 2010 , eram mulheres. Contudo existe uma elevada assimetria entre gêneros, dependendo do curso superior: enquanto mais de $80 \%$ dos formandos dos cursos de Educação, Línguas, Enfermagem e Fisioterapia pertencem ao sexo feminino, menos de $30 \%$ dos graduados em Computação e Engenharias são mulheres. De acordo com Nogueira (2012, p. 6), há uma certa unanimidade na literatura educacional no sentido de que as mulheres optam por cursos que não estão nas Ciências Exatas. Usualmente, as mulheres acabam por se autosselecionar para as carreiras ligadas às Ciências da Vida ou Humanas.

Cabe destacar que, com exceção de Jornalismo, Computação e Arquitetura, os demais cursos apresentaram decréscimos no diferencial de formados por gênero, entre 2000 e 2010.

Com relação à cor, verifica-se que o percentual de negros com ensino superior completo aumentou 11,72 p.p. entre 2000 e 2010. Este comportamento foi observado em todos os cursos superiores, contudo, nas áreas de Arquitetura e Medicina, os indivíduos que se declararam negros representavam apenas $15 \%$ do total. Por outro lado, mais de $30 \%$ dos

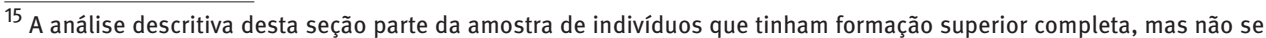
restringe àqueles com idade entre 26 e 28 anos, amostra utilizada na estimação econométrica. A ideia principal nesta seção é descrever o perfil dos indivíduos que tinham concluído a etapa de educação superior.
} 
graduados em Educação, Enfermagem, Física e Matemática declararam-se negros ao Censo Demográfico de 2010, conforme mostra a Tabela 3.

TABELA 3

Dados sobre os indivíduos com o ensino superior completo, segundo cursos selecionados Brasil - 2000-2010

\begin{tabular}{|c|c|c|c|c|c|c|c|c|}
\hline Cursos & Anos & $\begin{array}{c}\text { Total com } \\
\text { ensino } \\
\text { superior } \\
\text { completo (\%) }\end{array}$ & $\begin{array}{c}\text { Mulheres } \\
\text { (\%) }\end{array}$ & $\begin{array}{c}\text { Negros } \\
(\%)\end{array}$ & $\begin{array}{l}\text { Idade } \\
\text { média } \\
\text { (anos) }\end{array}$ & $\begin{array}{l}\text { Salário } \\
\text { hora } \\
\text { médio } \\
\text { (RS) (1) }\end{array}$ & $\begin{array}{c}\text { Taxa de } \\
\text { ocupação } \\
\text { (\%) }\end{array}$ & $\begin{array}{c}\text { Renda } \\
\text { domiciliar per } \\
\text { capita média } \\
\text { (RS) (1) }\end{array}$ \\
\hline \multirow{2}{*}{ Administração } & 2000 & 15,74 & 41,20 & 11,73 & 38,76 & 19,07 & 83,77 & 948,73 \\
\hline & 2010 & 18,64 & 49,97 & 22,90 & 37,01 & 18,91 & 87,56 & $1.194,55$ \\
\hline \multirow{2}{*}{ Arquitetura } & 2000 & 2,72 & 48,33 & 8,74 & 38,47 & 18,49 & 87,01 & $1.213,55$ \\
\hline & 2010 & 1,90 & 56,33 & 13,51 & 37,77 & 22,91 & 86,54 & $1.678,10$ \\
\hline \multirow{2}{*}{ Biologia } & 2000 & 3,11 & 75,28 & 14,58 & 38,77 & 13,43 & 82,81 & 955,98 \\
\hline & 2010 & 1,85 & 73,26 & 25,75 & 36,38 & 14,77 & 80,23 & $1.191,60$ \\
\hline \multirow{2}{*}{ Computação } & 2000 & 3,18 & 40,29 & 11,51 & 31,47 & 16,14 & 89,95 & $1.024,19$ \\
\hline & 2010 & 3,82 & 28,05 & 22,34 & 33,17 & 19,05 & 90,36 & $1.221,72$ \\
\hline \multirow{2}{*}{ Contabilidade } & 2000 & 7,21 & 45,61 & 17,54 & 39,33 & 14,86 & 83,37 & 758,57 \\
\hline & 2010 & 5,62 & 49,68 & 27,23 & 40,34 & 18,31 & 86,56 & $1.030,35$ \\
\hline \multirow{2}{*}{ Direito } & 2000 & 15,29 & 44,27 & 12,96 & 41,14 & 23,59 & 82,01 & $1.093,77$ \\
\hline & 2010 & 11,44 & 49,56 & 19,53 & 38,65 & 30,19 & 84,33 & $1.555,37$ \\
\hline \multirow{2}{*}{ Economia } & 2000 & 4,78 & 35,29 & 13,59 & 42,50 & 23,22 & 81,69 & 995,54 \\
\hline & 2010 & 2,02 & 41,02 & 19,33 & 44,25 & 29,08 & 81,26 & $1.411,52$ \\
\hline \multirow{2}{*}{ Educação (2) } & 2000 & 17,02 & 92,26 & 19,03 & 41,46 & 10,44 & 76,09 & 844,67 \\
\hline & 2010 & 25,57 & 83,89 & 35,19 & 40,41 & 12,48 & 83,18 & 911,26 \\
\hline \multirow{2}{*}{ Enfermagem } & 2000 & 2,17 & 92,25 & 24,46 & 38,30 & 13,07 & 84,65 & 946,56 \\
\hline & 2010 & 3,27 & 87,51 & 33,82 & 34,37 & 14,04 & 81,42 & $1.089,22$ \\
\hline \multirow{2}{*}{ Engenharia } & 2000 & 10,54 & 15,08 & 10,29 & 41,07 & 25,70 & 89,33 & 991,98 \\
\hline & 2010 & 6,70 & 17,23 & 17,83 & 40,57 & 32,46 & 88,89 & $1.370,41$ \\
\hline \multirow{2}{*}{ Física } & 2000 & 3,49 & 59,25 & 19,45 & 41,08 & 14,72 & 83,64 & 797,27 \\
\hline & 2010 & 1,71 & 54,82 & 31,10 & 40,38 & 18,33 & 83,21 & $1.042,22$ \\
\hline \multirow{2}{*}{ Fisioterapia } & 2000 & 1,91 & 87,73 & 12,61 & 34,28 & 13,57 & 81,38 & $1.215,29$ \\
\hline & 2010 & 2,91 & 85,61 & 20,16 & 32,62 & 15,45 & 82,42 & $1.513,95$ \\
\hline \multirow{2}{*}{ Jornalismo } & 2000 & 1,19 & 60,31 & 12,12 & 36,85 & 19,90 & 83,11 & $1.183,59$ \\
\hline & 2010 & 1,75 & 62,02 & 21,58 & 35,77 & 18,93 & 83,27 & $1.554,91$ \\
\hline \multirow{2}{*}{ Línguas } & 2000 & 0,89 & 88,21 & 14,64 & 41,58 & 13,61 & 78,25 & $1.011,85$ \\
\hline & 2010 & 5,67 & 86,66 & 30,94 & 41,02 & 14,05 & 81,23 & $1.047,31$ \\
\hline \multirow{2}{*}{ Matemática } & 2000 & 3,59 & 62,62 & 16,67 & 39,83 & 13,59 & 86,45 & 796,90 \\
\hline & 2010 & 1,75 & 58,60 & 27,44 & 41,55 & 17,14 & 85,34 & 981,05 \\
\hline \multirow{2}{*}{ Medicina } & 2000 & 5,64 & 39,80 & 11,24 & 41,26 & 31,16 & 94,09 & $1.236,06$ \\
\hline & 2010 & 2,41 & 46,68 & 14,96 & 42,07 & 43,51 & 92,90 & $1.969,58$ \\
\hline \multirow{2}{*}{ Publicidade } & 2000 & 1,61 & 59,75 & 8,35 & 34,48 & 16,47 & 82,01 & $1.332,86$ \\
\hline & 2010 & 3,05 & 55,90 & 17,78 & 33,82 & 19,39 & 86,58 & $1.501,40$ \\
\hline \multirow{2}{*}{ Média Brasil } & 2000 & - & 53,11 & 14,20 & 39,91 & 18,86 & 83,47 & 976,14 \\
\hline & 2010 & - & 60,79 & 25,92 & $38,, 64$ & 19,81 & 85,13 & $1.206,12$ \\
\hline
\end{tabular}

Fonte: IBGE. Microdados dos Censos Demográficos de 2000 e 2010. Elaboração dos autores.

(1) Valores em reais de 2010. Para o cálculo da renda domiciliar per capita, excluiu-se o rendimento do próprio indivíduo.

(2) Refere-se à grande área de formação de docentes que engloba "formação de docentes para a educação básica" ou "formação de professores" (agrupando formações em licenciaturas). 
Mesmo com os avanços deflagrados pelas políticas de cotas, conforme já elucidado brevemente na introdução, persistem diferenças, sobretudo no acesso aos chamados cursos de prestígio, como Medicina ou Odontologia. Há ainda um processo de autosseleção na dimensão de raça/cor, possivelmente devido ao fato de os dados se referirem a 2010 , quando os possíveis efeitos desta mudança no cenário institucional não tenham sido tão expressivos.

De todo modo, como já pontuado por vários autores, tais como Nogueira (2012), Paul e Silva (1998) e o trabalho mais antigo de Gouveia (1970), a etnia e o gênero são definidores da trajetória educacional dos indivíduos, sobretudo, no que tange ao tipo de formação superior escolhida.

Quanto à idade média dos profissionais, observa-se que para as áreas de Economia, Contabilidade, Matemática, Computação e Medicina houve uma elevação entre 2000 e 2010, enquanto nas demais ocorreu redução da idade média, no mesmo período (Tabela 3).

Nota-se que os rendimentos médios por hora trabalhada apresentam elevada variação, dependendo do curso concluído pelo indivíduo. Profissionais formados em Medicina, Engenharias e Economia ganhavam, em média, entre duas e três vezes mais do que pessoas formadas em cursos de Biologia, Educação, Enfermagem e Línguas, em 2000, sendo que essa diferença aumentou em 2010 (Tabela 3). Ressalta-se que, no período analisado, a remuneração média para profissionais de Medicina cresceu $39,63 \%$, enquanto aquela de pessoas formadas em Línguas ampliou-se em 3,22\%. Quanto ao percentual de pessoas ocupadas dentre as formadas em cada curso superior, a Tabela 3 mostra que, em 2010, nenhuma área possuía uma taxa de ocupação inferior a $80 \%$, sendo que os graduados em Medicina e Computação apresentaram resultados superiores a $90 \%$.

Por fim, os rendimentos domiciliares per capita exclusive o rendimento do próprio indivíduo também apresentam elevada variação quanto à formação do indivíduo. Nota-se que, entre 2000 e 2010, o rendimento domiciliar per capita aumentou em todos os domicílios com residentes de escolaridade de nível superior completo, contudo, tal crescimento percentual foi maior naqueles com profissionais formados em Medicina e Engenharia. Contudo, em 2010, domicílios com profissionais das áreas de Educação e Matemática apresentavam $r d p c$ inferior a $\mathrm{R} \$ 1.000$, enquanto aqueles com profissionais das carreiras de Medicina $\mathrm{e}$ Arquitetura possuíam rendimentos per capita superiores a $\mathrm{R} \$ 1.600$.

De modo geral, as estatísticas descritivas mostraram a existência de diferenças entre os cursos superiores analisados, o que intensifica a necessidade de uma análise segmentada para cada curso. Esta análise nos permitiu já inferir que os indivíduos podem se deparar com características dos cursos similares, tais como duração/concorrência e oportunidades profissionais futuras, mas, tendo em vista suas condições em termos econômicos ou de inserção na sociedade, podem fazer escolhas diversas. Na literatura, sobretudo sociológica, sobre ingresso no ensino superior (NOGUEIRA, 2012; PAUL; SILVA, 1998; dentre outros), bem como na literatura econômica (MARQUES, 2011; MENDES JUNIOR, 2014), constata-se que alunos com melhores condições socioeconômicas usualmente seguem carreiras mais 
prestigiadas e com retornos financeiros futuros maiores, tais como Medicina ou Direito. A origem social, portanto, define fortemente a trajetória dos indivíduos, delegando aos mais pobres, às mulheres e aos não brancos vagas em cursos superiores de menor prestígio ou com um perfil muito particular. Por exemplo, há um percentual significativo de mulheres nas cadeiras de humanas ou biológicas em detrimento de um menor número nas áreas de tecnologia ou exatas. Assim, a estratificação educacional existe nos anos 2000 , com o agravante de também ter um componente que não tem origem somente na questão de recursos financeiros, mas igualmente numa discriminação por gênero/etnia. Após as mudanças institucionais operadas ao longo dos anos 2000, eventualmente, podemos ter um cenário com menor estratificação, contudo, nossa análise centra-se em um período anterior pela própria limitação dos dados. Dessa forma, na próxima seção, abordaremos se as características dos cursos, bem como as características individuais, influenciam e condicionam a escolha da formação superior concluída e se estes efeitos são diferenciados segundo a classe de renda domiciliar.

\section{Metodologia econométrica}

Para analisar empiricamente a escolha do tipo de curso de educação superior, utilizamos o modelo logit condicional, conforme McFadden (1973). ${ }^{16}$ Por meio desta modelagem empírica, pode-se estimar a probabilidade de uma pessoa eleger um curso superior dentro do seu leque de opções de cursos disponíveis. Assim, a partir desse modelo, conseguimos especificar dois conjuntos de variáveis: um que apresenta variação em função das alternativas disponíveis ao indivíduo; e outro que varia em função do próprio indivíduo.

Como variáveis do conjunto de opções dos cursos superiores, ${ }^{17}$ têm-se o rendimento esperado no início da cada carreira, a variabilidade salarial, a taxa de desemprego da carreira, a concorrência no processo seletivo e a duração do curso. Já as variáveis referentes aos indivíduos consistem em cor, idade e sexo, assim como quartil de rdpc exclusive o rendimento do próprio indivíduo e região de residência.

Em seguida, a amostra é expandida em função dos 17 cursos possíveis de serem escolhidos e controlamos para as variáveis relativas aos diferentes cursos e diferentes características pessoais, conforme equação (1).

$\operatorname{Prob}\left(\mathrm{Y}_{\mathrm{j}}\right)=\beta \mathrm{S}_{\mathrm{j}}+\beta_{1} \mathrm{X}_{\mathrm{i}}$

Onde: $\mathrm{Y}_{\mathrm{j}}$ representa o curso $j ; \mathrm{S}_{\mathrm{j}}$ é o conjunto de fatores que variam em função do curso; e $\mathrm{X}_{\mathrm{i}}$ corresponde ao conjunto de fatores que variam em função do indivíduo.

Para fins de interpretação do modelo, um coeficiente positivo indica uma relação positiva entre a variável e a probabilidade de o curso $j$ ser escolhido. Depois da estimação,

\footnotetext{
16 Para mais detalhes, consultar MacFadden (1973) e Cameron e Trivedi (2005).

17 o Anexo apresenta os valores atribuídos a cada uma das variáveis em função de cada curso superior.
} 
extraímos os efeitos marginais das características individuais, para analisarmos o impacto de cada uma no processo de escolha dos indivíduos por curso superior.

\section{Resultados econométricos}

Como resposta do logit condicional com alternativas especificadas, são obtidos um resultado geral para as características relativas aos diferentes cursos e sobre os incentivos econômicos de cada carreira e um resultado referente aos efeitos das características individuais para cada curso, reportados na Tabela 4 para a amostra de indivíduos de 26 a 28 anos em 2010.

Além das características individuais, os primeiros modelos consideraram aquelas relativas à institucionalidade do curso (concorrência e tempo de duração). Por seu turno, os modelos seguintes incorporaram gradativamente as variáveis ligadas à carreira (taxa de desemprego, desvio do rendimento médio e rendimento no início da carreira). Cabe lembrar que as variáveis individuais são incluídas em todos os modelos e as estimações foram realizadas segmentadas pelo quartil de rendimento domiciliar per capita. ${ }^{18}$

0 primeiro modelo apresenta o efeito da concorrência do processo seletivo na escolha pelo curso. Notam-se um efeito negativo da concorrência para as pessoas do primeiro quartil de $r d p c$ na amostra dos indivíduos de 26 a 28 anos (Tabela 4) e um impacto positivo para as pessoas do quartil mais elevado de renda.

Possivelmente, para os mais jovens com menor defasagem idade-série entre os mais pobres, é importante entrar logo na universidade. Dessa forma, podem priorizar a decisão sobre o tipo de curso com base na relação candidato/vaga, escolhendo os cursos em que a chance de passar no vestibular é maior, pois a concorrência de vagas é menor, sendo por esse motivo que o coeficiente é negativo.

Já para os que estão na escala superior da renda domiciliar per capita, cursos mais concorridos são os mais prestigiados e que oferecem retorno mais alto no longo prazo. Nesse sentido, o sinal positivo do coeficiente é explicado pelo fato de que, para estes indivíduos, o custo de o ingresso num primeiro momento não ser bem-sucedido devido à alta concorrência não é tão grande, podendo tentar novamente em outro ano. Logo, a probabilidade de escolha por estes cursos aumenta para os que estão na classe de renda domiciliar mais alta.

Ao ser incorporada a variável de duração do curso, verificamos que a intensidade da variável de concorrência aumenta para o primeiro quartil de $r d p c$ da amostra dos mais jovens (Tabela 4). Registre-se que essa variável só se mostrou significativa para esta

\footnotetext{
18 Também incluímos interações entre cor e gênero. Apenas conseguimos estimar o modelo que incorporava a dummy de sexo e a interação entre ela e a dummy de cor. Os modelos que incluíam as dummies de cor e sexo e as interações não convergiram sob diferentes especificações, cortes de idade e amostras.
} 
amostra quando estimada isoladamente. ${ }^{19}$ Contudo, para os extratos mais altos da renda, observamos que o resultado encontrado anteriormente não permanece.

0 terceiro modelo destacado na Tabela 4 acrescenta a variável de rendimento no início da carreira ao modelo 2. Percebe-se que os indivíduos do primeiro quartil de $r d p c$ continuam sendo influenciados negativamente pela concorrência, enquanto as pessoas do outro extremo de $r d p c$ são influenciadas negativamente. 0 rendimento do início da carreira afeta positivamente pessoas nos dois extratos extremos da distribuição de renda. Ou seja, existe uma maior demanda pelos cursos com os maiores retornos iniciais.

As outras variáveis ligadas à carreira incorporadas nas estimações foram a taxa de desemprego e a dispersão salarial, no quarto modelo. Como esperado, para o quartil de $r d p c$ mais elevado, a taxa de desemprego possui um impacto negativo, isto é, as pessoas preferem cursos com menor exposição ao desemprego. 0 rendimento de início da carreira continuou significativo e positivo para o quartil mais elevado de $r d p c$. Com a inclusão do desvio do rendimento, nota-se que as pessoas do quartil mais elevado de $r d p c$ possuem uma maior propensão a se arriscarem em carreiras com maior dispersão salarial. Para o primeiro quartil de $r d p c$ nada foi significativo.

Temos que as pessoas da amostra mais jovem do quartil mais elevado de $r d p c$ preferem cursos com maiores rendimentos do início da carreira, não possuem aversão ao risco e temem o desemprego. Por seu turno, para as pessoas do primeiro quartil de $r d p c$ os parâmetros não foram significativos.

Considerando as variáveis individuais, a Tabela $4^{20}$ destaca os coeficientes das dummies referentes ao sexo feminino e da sua interação com a cor negra. ${ }^{21} \mathrm{~A}$ primeira indica que as mulheres possuem maior probabilidade de escolher Educação, que é o curso de referência, em comparação com qualquer outro curso. Os coeficientes dos demais cursos são negativos, ou, quando positivos, não significativos, como no caso de Línguas no terceiro quartil de $r d p c$. As exceções ocorrem no quartil mais elevado para os cursos de Fisioterapia, Enfermagem e Línguas, em que o coeficiente é positivo e significativo. Ou seja, para o quartil mais elevado, as mulheres preferem estes três cursos (Fisioterapia, Enfermagem e Línguas) ao curso de Educação.

Com relação à interação da cor, verificamos que as mulheres negras possuem menores chances de escolherem qualquer curso superior quando comparado ao de Educação. Cabe salientar que para outros cursos foram encontrados resultados não significativos para um dos quartis de $r d p c$, como nos de Línguas e Matemática.

\footnotetext{
19 Influenciando positivamente as pessoas do quartil de rdpc mais elevado.

20 Cabe destacar a extrema estabilidade dessas variáveis nos diferentes modelos estimados; sendo assim, será feita apenas uma interpretação geral dos seus coeficientes.

${ }^{21}$ Registre-se que todos os modelos foram estimados controlando-se para a idade, idade ao quadrado e região de moradia.
} 


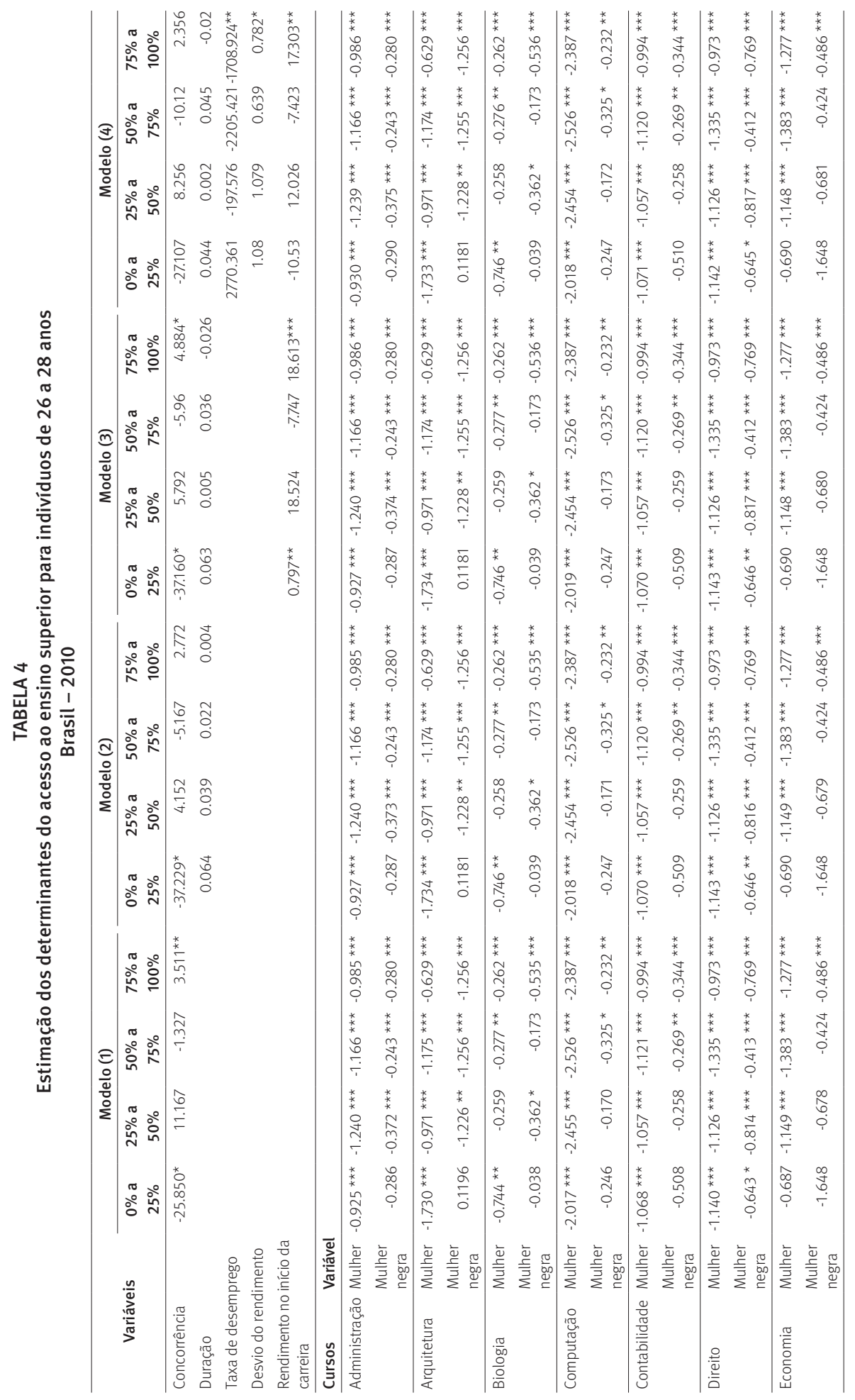




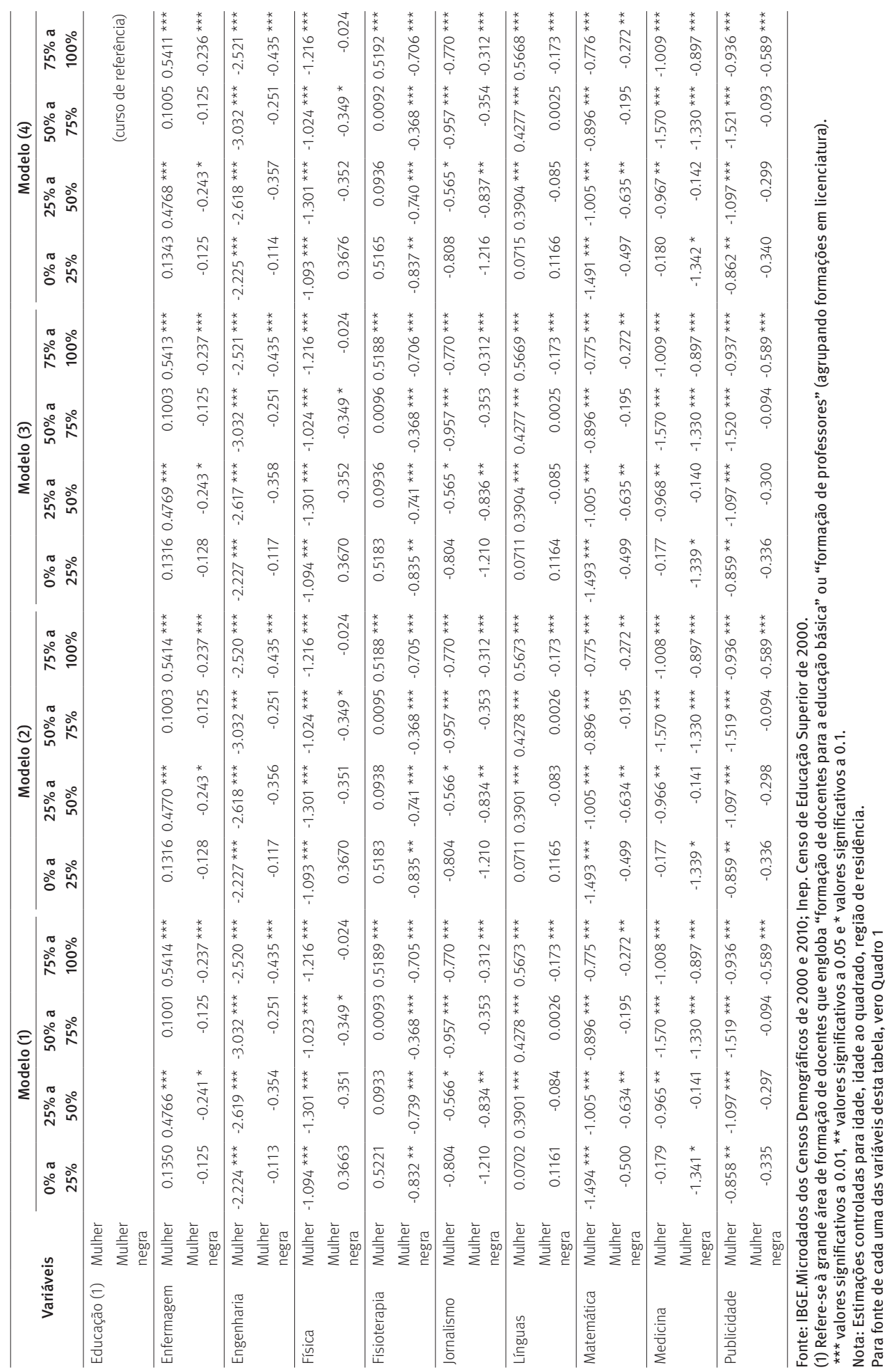




\section{Considerações finais}

Conforme apresentado pelas estimações baseadas nos dados do Censo Demográfico de 2010, as pessoas do quartil de renda domiciliar per capita mais elevado são influenciadas positivamente pelo retorno esperado na hora da escolha por qual curso superior demandar, seja no início ou ao longo da carreira. Já a concorrência pela vaga mostrou grande impacto negativo na tomada de decisão dos indivíduos do quartil mais baixo de $r d p c$. Pessoas de classes mais baixas consideram a concorrência uma das barreiras ao ingresso e acabam escolhendo cursos mais fácies de passar no exame de ingresso. Além disso, dependendo do curso superior escolhido, os fatores individuais influenciam positiva ou negativamente a probabilidade de escolha do curso.

Os dados mostram que a decisão pela formação do nível superior está condicionada às características individuais, tais como idade, sexo, cor e quartil de $r d p c$. Os resultados estão, na verdade, alinhados com alguns já apresentados pela literatura, sugerindo que a trajetória educacional, sobretudo a escolha da formação no nível superior, está delimitada de alguma forma pelas condições socioeconômicas do indivíduo e até por suas características individuais, tais como a etnia ou o sexo. A influência dos fatores específicos do curso, tais como rendimento no início de carreira, concorrência, duração do curso e perspectivas de estar empregado, para o processo decisório, está atrelada à posição do indivíduo na distribuição de renda e na sociedade.

Vale destacar que esse artigo foi elaborado com os dados de 2010, de forma a tirar conclusões sobre o processo decisório dos jovens no ano de ingresso na educação superior usando dados de 2000. Ao longo deste período, conforme pontuado na introdução, o Brasil passou por inúmeras mudanças institucionais no ensino superior, sobretudo na forma de acesso à universidade (surgiram as políticas de cotas e o Sisu). 0 processo de avaliação passou a ser mais centralizado em torno dos resultados do Enem, facilitando a escolha do curso por parte dos candidatos no momento posterior à divulgação das notas. A incerteza na escolha é reduzida a partir do momento que a opção pode ser feita depois da divulgação da nota individual. Este processo, portanto, pode ter efeitos mais amplos no impacto da concorrência sobre as escolhas. Da mesma forma, espera-se que as políticas de cotas contribuam para reduzir a autosseleção no ensino superior.

\section{Referências}

AGUAS, M.; MACHADO, D. C. Secondary vocational education and earnings in Brazil. In: II ENCONTRO DE ECONOMIA APLICADA. Anais...Juiz de Fora-MG: UFJF, 2016. Disponível em: 〈http:// www.ufjf.br/encontroeconomiaaplicada/files/2016/05/artig089economiasocialetrabalho_ identificado.pdf〉.

ALTONJI, J. G. The demand for and return to education when education outcomes are uncertain. Journal of Labor Economics, v. 11, n. 1, p. 48-83, 1993. 
ALTONJI, J. G.; BLOM, E.; MAGHIR, C. Heterogeneity in human capital investments: high school curriculum, college major, and careers. Cambridge, MA: NBER, 2012 (Working Paper NBER, n. 17985).

BARTALOTTI, O.; MENEZES FILHO, N. A relação entre o desempenho da carreira no mercado de trabalho e a escolha profissional dos jovens. Economia Aplicada, São Paulo, v. 11, n. 4, p.487505, 2007.

BERGER, M. C. Predicted future earnings and choice of college major. Industrial and Labor Relations Review, v. 41, n. 3, p.418-429, Apr. 1988.

CAMERON, A. C.; TRIVERDI, P. K. Microeconometrics. New York: Cambridge University Press, 2005.

CARVALHO, M. M. A educação superior no Brasil: o retorno privado e as restrições ao ingresso. Sinais Sociais, Rio de Janeiro, v. 5, n. 15, p. 82-111, 2011.

CASARI, P. Retorno esperado e escolha profissional: fatores associados à escolha da carreira dos alunos da Universidade de São Paulo. Dissertação (Mestrado em Economia) - Faculdade de Economia, Administração e Contabilidade, Universidade de São Paulo, São Paulo, 2006.

EMILIO, D. R.; BELLUZZO JUNIOR, W.; ALVES, D. C. O. Uma análise econométrica dos determinantes do acesso à Universidade de São Paulo. Pesquisa e Planejamento Econômico, Rio de Janeiro, v. 34, n. 2, p. 275-306, 2004.

DURU, M.; MINGAT, A. Comportement des bacheliers: modèle de choix de disciplines. Revue Consommation, v. 34, p. 245-262, 1979.

FREEMAN, R. B. A cobweb model of the supply and starting salary of new engineers. Industrial and Labour Relations Review, v. 30, n. 2, p. 236-48, 1976.

IBGE - Instituto Brasileiro de Geografia e Estatística. Documentação dos microdados da amostra - Censo Demográfico 2000. Rio de Janeiro, novembro 2002.

Documentação dos microdados da amostra - Censo Demográfico 2010. Rio de Janeiro, abril 2011.

INEP. Tabelas da Sinopse Estatística da Educação Superior - Graduação. 2012. Disponível em: 〈http://inep.gov.br/sinopses-estatisticas-da-educacao-superior〉. Acesso em: ago. 2018.

MACHADO, C.; SZERMAN, C. Centralized admission and the student-college match. Bonn: IZA, Sep. 2016 (Discussion Paper n. 10251).

MENDES JUNIOR, A. A. F. Uma análise da progressão dos alunos cotistas sob a primeira ação afirmativa brasileira no ensino superior: o caso da Universidade do Estado do Rio de Janeiro. Ensaio: Avaliação de Políticas Públicas Educacionais, Rio de Janeiro, v. 22, n. 82, p. 31-56, 2014.

GOUVEIA, A. J. Origem étnica e situação socioeconômica dos estudantes matriculados em diferentes áreas de estudo nas universidades de São Paulo. América Latina, ano 13, n. 4, p. 33-48, 1970.

LI, L. D.; CHAGAS, A.L.S. Efeitos do SISU sobre a migração e a evasão estudantil. In: XV ENCONTRO NACIONAL DA ASSOCIAÇÃO BRASILEIRA DE ESTUDOS REGIONAIS E URBANOS. Anais... São Paulo: Aber, 2017. Disponível em: 〈http://sisconev.com.br/Uploads/ENABER17/ Trab01570036202017006_000000.pdf〉.

MCFADDEN, D. Conditional logit analysis of qualitative choice behaviour. In: INTERNATIONAL CONFERENCE ON SPATIAL INFORMATION THEORY. Proceedings... Bastad, Sweden, 1973. 
MONT’ALVÃO, A. Estratificação educacional no Brasil do século XXI. Dados - Revista de Ciências Sociais, Rio de Janeiro, v.54, n.2, p. 389-430, 2011.

MONTMARQUETTE, C.; CANNINGS, K.; MAHSEREDJIAN, S. How do young people choose college majors? Economics of Education Review, v. 21, n. 6, p. 543-556, Dec. 2002.

NOGUEIRA, C. M. M. Escolha racional ou disposições incorporadas: diferentes referenciais teóricos na análise sociológica do processo de escolha dos estudos superiores. Estudos de Sociologia, v. 2, n. 18, 2012.

PAGLIN, M.; RUFOLO, A. Heterogeneous human capital, occupational choice, and male-female earnings differences .Journal of Labor Economics, Chicago, v. 8, n. 1, p. 123-144, 1990.

PAUL, J.-J.; SILVA, N. V. Conhecendo o seu lugar: a auto-seleção na escolha de carreira. Revista Brasileira de Política e Administração da Educação, v.14, n. 1, p. 115-130, 1998.

SCHWARTZMAN, S. Aprendendo com os erros e acertos do passado: pontos essenciais para a definição de políticas públicas de Educação Superior. In: III CONGRESSO BRASILEIRO DE EDUCAÇÃO SUPERIOR PARTICULAR. Anais... Florianópolis: Fórum das Entidades Representativas do Ensino Superior Particular, abril 2010.

SOARES, F. L. B. A escolha no ensino superior: fatores de decisão. 2007. 126 f. Dissertação (Mestrado em Economia) - Faculdade de Ciências Econômicas, Universidade Federal do Rio Grande do Sul, Porto Alegre, 2007.

SILVA, D.F. C. da; NETO, R.M.S. Escolhas de carreiras universitárias e mercado de trabalho: uma análise da influência dos incentivos econômicos. Nova Economia, Belo Horizonte, v. 25, n. 3, p. 519-552, set./dez. 2015.

\section{Sobre os autores}

Felipe dos Santos Martins é doutorando da Faculdade de Economia da Universidade Federal Fluminense (UFF) e mestre em Economia pela UFF. Assistente de pesquisa no Instituto de Pesquisa Econômica Aplicada (Ipea/Rio).

Danielle Carusi Machado é doutora pelo Departamento de Economia da Pontifícia Universidade Católica do Rio de Janeiro (PUC-Rio) e mestre pelo Instituto de Economia da Universidade Federal do Rio de Janeiro (UFRJ). Professora associada da Faculdade de Economia da Universidade Federal Fluminense (UFF).

\section{Endereço para correspondência}

\section{Felipe dos Santos Martins}

Avenida Oswaldo Cruz, 96, apt. 1205, Flamengo

22250-060 - Rio de Janeiro-RJ, Brasil

Danielle Carusi Machado

Rua Tiradentes, 171, bloco 1, apt. 1301, Ingá

24210-510 - Niterói-RJ, Brasil

\section{Agradecimentos}

Agradecemos aos componentes da banca de dissertação de mestrado de Felipe Martins (Maurício Reis e Fábio D. Waltenberg) e aos participantes do Seminário de Pesquisa do Ipea e 
do Seminário de Pesquisa do IE/UFRJ. Agradecemos, ainda, aos pareceristas anônimos desta revista, que contribuíram de forma significativa para melhorar este artigo, bem como à Capes pelo apoio ao longo do mestrado de Felipe Martins.

\section{Abstract}

\section{An analysis of the choice of higher education in Brazil}

The aim of this paper is to evaluate the factors conditioning the choice of type of higher education course in Brazil. Based on data from the 2000 and 2010 Demographic Censuses and the Higher Education Synopsis from2000, we model the choice of course by the individual using the conditional logit model. The variables that affect this choice are: individual and family characteristics; candidate-vacancy relationship (competition) and course duration; income (mean and variability) and unemployment. This analysis is done for the total number of individuals with the age required for college entrance examination in the year 2000. The results indicated that expected yields, unemployment rate and the wage variability of careers only influence the individuals of the highest quartile. On the other hand, competition in the selective process has a greater impact on the choice of individuals in the lower distribution quartile.

Keywords: Demand for higher education. Heterogeneous human capital. Determinants of access to higher education.

\section{Resumen}

Un análisis de la elección del curso superior en Brasil

El objetivo del artículo es evaluar los factores que influyen en la elección del tipo de curso superior en Brasil. A partir de los datos de los censos demográficos de 2000 y 2010 y de la Sinopsis de Educación Superior de 2000, modelamos la elección del curso por parte del individuo usando el modelo logit condicional. Las variables que condicionan esta elección son: características individuales y familiares; relación candidato-vacante y el tiempo de duración del curso e incentivos económicos de las carreras (media y variabilidad del rendimiento y desempleo). Este análisis fue hecho para el total de individuos en edad de presentarse al vestibular en el año 2000. Los resultados indicaron que los ingresos y la tasa de desempleo influyen solo en los indivíduos del cuartil más elevado. La competencia tiene mayor impacto en la elección de los individuos del cuartil inferior de distribución.

Palabras claves: Enseñanza superior. Capital humano heterogéneo. Acceso a la enseñanza superior. 


\section{Anexo}

TABELA 1

Classificação do Censo e variáveis dos cursos

\begin{tabular}{lcccc}
\hline \multicolumn{1}{c}{ Cursos } & Classificação Censo Demográfico & $\begin{array}{c}\text { Rendimento } \\
\text { esperado ao } \\
\text { longo da carreira }\end{array}$ & $\begin{array}{c}\text { Rendimento } \\
\text { esperado do } \\
\text { início da carreira }\end{array}$ & Concorrência \\
\hline Administração & $340-341-343-345$ & 12.76 & 6.98 & 2.19 \\
Arquitetura & 581 & 12.38 & 6.89 & 3.11 \\
Biologia & 421 & 8.97 & 5.49 & 4.56 \\
Computação & $481-483$ & 10.77 & 7.71 & 2.66 \\
Contabilidade & 344 & 9.98 & 5.49 & 1.99 \\
Direito & 380 & 16.23 & 8.67 & 4.57 \\
Economia & 314 & 15.7 & 7.58 & 2.11 \\
Educação (1) & $140-142-143-144-145-146$ & 7.03 & 4.69 & 2.4 \\
Enfermagem & 723 & 8.68 & 7.34 & 5.03 \\
Engenharias & $520-521-522-523-524-525$ & 17.32 & 9.32 & 3.55 \\
Física & 440 & 9.87 & 6.2 & 3.27 \\
Fisioterapia & 726 & 9.06 & 6.68 & 3.82 \\
Jornalismo & 321 & 13.46 & 7.34 & 3.25 \\
Línguas & $222-223$ & 9.21 & 6.74 & 3.93 \\
Matemática & $461-462$ & 9.11 & 5.88 & 3.52 \\
Medicina & 721 & 21.23 & 10.19 & 32.65 \\
Publicidade & 342 & 11.04 & 7.74 & 2.75 \\
\hline
\end{tabular}

Fonte: IBGE. Microdados dos Censos Demográficos de 2000 e 2010. MEC-Inep; Deed - Inep (2012). Elaboração dos autores. (1) Refere-se à grande área de formação de docentes que engloba "formação de docentes para a educação básica" ou "formação de professores" (agrupando formações em licenciatura).

TABELA 2

Estatísticas descritivas das variáveis usadas no modelo econométrico

\begin{tabular}{lrrr}
\hline \multicolumn{1}{c}{ Variável } & Média & Mínimo & Máximo \\
\hline Feminino (\%) & 63,1 & 0,0 & 100,0 \\
Negro (\%) & 44,3 & 0,0 & 100,0 \\
Mulher Negra (\%) & 17,6 & 0,0 & 100,0 \\
Idade (anos) & 27,05 & 26,00 & 28,00 \\
Salário por hora (R\$) & 11,70 & - & $2.777,77$ \\
Renda domiciliar per capita (R\$) & $1.154,14$ & 0,17 & $7.125,00$ \\
Concorrência (pessoas por vaga) & 5,02 & 1,99 & 32,95 \\
Duração (carga horária) & $5.711,76$ & 4.800 & 9.600 \\
Taxa de desemprego (\%) & 4,30 & 1,44 & 7,47 \\
Desvio do rendimento hora (R\$) & 20,65 & 7,06 & 54,73 \\
Rendimento inicial (R\$) & 7,11 & 4,69 & 10,19 \\
\hline
\end{tabular}

Fonte: Censo Demográfico e Sinopse de Educação Superior. Consultar o Quadro 1 para ver a fonte de cada variável. 